\title{
Aspectos epidemiológicos, clínicos e anatomopatológicos do linfoma folicular em cães ${ }^{1}$
}

\author{
Renata D. Mazaro², Isis P.J. Rizkallah4, Flávia S. Luz², Douglas M. Lorensetti³ \\ Bruno Cogliati ${ }^{4}$ e Rafael A. Fighera ${ }^{5 *}$
}

\begin{abstract}
Mazaro R.D., Rizkallah I.P.J., Luz F.S., Lorensetti D.M., Cogliati B. \& Fighera R.A. 2018. [Epidemiological, clinical and pathological aspects of follicular lymphoma in dogs.] Aspectos epidemiológicos, clínicos e anatomopatológicos do linfoma folicular em cães. Pesquisa Veterinária Brasileira 38(9):1772-1780. Departamento de Patologia, Universidade Federal de Santa Maria, Av. Roraima 1000, Santa Maria, RS 97105-900, Brazil. E-mail: anemiaveterinaria@yahoo.com.br

Follicular lymphomas are a rare form of lymphoproliferative disorder described in veterinary medicine. Together with the probable non-existence of Hodgkin's lymphomas in dogs, this is the biggest difference about lymphoma between humans and dogs. The aim of this article is to describe the epidemiological, clinical and anatomopathological findings observed in five dogs with follicular lymphoma. Of the five dogs with follicular lymphoma, two were male (40\%) and three were female (60\%). The age of affected dogs ranged from 11 to 13 years. Four of the five $(80 \%)$ dogs were purebred and one $(20 \%)$ had no defined breed. All dogs presented generalized lymphadenomegaly and splenomegaly, which included cases as multicentric lymphoma. At necropsy, the lymph nodes and the spleen demonstrated a nodular pattern at the cut surface, characterized by tens to hundreds of white nodules of variable size, multifocal or coalescing. On the natural surface of the spleen, often $(4 / 5,80 \%)$, there were myriads of white, multifocal or coalescing dots of varying sizes. In histopathology, the tumors were confirmed as follicular lymphomas. All cases were Grade III, two (40\%) included as IIIa and three (60\%) as IIIb. In one case $(1 / 5,20 \%)$, follicular lymphoma was considered as a IIIb variant of small centroblasts similar to the neoplastic lymphocytes seen in Burkitt's lymphoma. Lymphomas were validated as having origin in B cells through immunohistochemistry, using anti-CD20 antibody. The cases of follicular lymphomas described behaved aggressively and led the patients to death.
\end{abstract}

INDEX TERMS: Epidemiology, clinics, pathology, lymphoma, dogs, follicular lymphoma, indolent lymphoma, multicentric lymphoma, diseases of dogs.

\footnotetext{
${ }^{1}$ Recebido em 24 de agosto de 2017.

Aceito para publicação em 15 de setembro de 2017.

${ }^{2}$ Programa de Pós-Graduação em Medicina Veterinária, área de concentração em Patologia e Patologia Clínica Veterinária, Centro de Ciências Rurais (CCR), Universidade Federal de Santa Maria (UFSM), Av. Roraima 1000, Camobi, Santa Maria, RS 97105-900, Brasil.

${ }^{3}$ Bolsista PIBIC/CNPq/UFSM, Curso de Medicina Veterinária, Centro de Ciências Rurais (CCR), Universidade Federal de Santa Maria (UFSM), Santa Maria, RS.

${ }^{4}$ Laboratório de Patologia Morfológica e Molecular (Lapmol), Faculdade de Medicina Veterinária e Zootecnia (FMVZ), Universidade de São Paulo (USP), Avenida Prof. Dr. Orlando Marques de Paiva 87, Cidade Universitária, Butantã, São Paulo, SP 05508-270, Brasil.

${ }^{5}$ Departamento de Patologia, Centro de Ciências da Saúde (CCS), Universidade Federal de Santa Maria (UFSM), Av. Roraima 1000, Camobi, Santa Maria, RS 97105-900.*Autor para correspondência: anemiaveterinaria@yahoo.com.br
}

RESUMO.- Linfomas foliculares são uma rara forma de distúrbio linfoproliferativo descrita em medicina veterinária. Juntamente com a não reconhecida ocorrência dos linfomas de Hodgkin em cães, essa é a maior diferença acerca de linfoma entre humanos e cães. $\mathrm{O}$ objetivo deste artigo é descrever os achados epidemiológicos, clínicos e anatomopatológicos vistos em cinco cães com linfoma folicular. Destes, dois eram machos (40\%) e três eram fêmeas (60\%). A idade dos cães afetados variou de 11 a 13 anos. Quatro dos cinco (80\%) cães eram de raça pura e um (20\%) não tinha raça definida. Todos os cães apresentaram linfadenomegalia generalizada e esplenomegalia, o que incluiu os casos como linfoma multicêntrico. Na necropsia, os linfonodos e o baço 
demonstraram um padrão nodular à superfície de corte, caracterizado por dezenas a centenas de nódulos brancos, multifocais ou coalescentes e de tamanhos variáveis. Na superfície natural do baço, frequentemente $(4 / 5,80 \%)$, havia miríades de pontos brancos, multifocais ou coalescentes, de tamanhos variáveis. Na histopatologia, os tumores foram confirmados como linfomas foliculares. Todos os casos eram Grau III, sendo dois (40\%) incluídos como IIIa e outros três (60\%) como IIIb. Em um caso (1/5, 20\%), o linfoma folicular foi considerado como IIIb variante de pequenos centroblastos semelhantes aos linfócitos neoplásicos vistos no linfoma de Burkitt. Os linfomas foram validados como tendo origem em células B através da imuno-histoquímica, utilizando anticorpos anti-CD20. Os casos de linfomas foliculares descritos comportaram-se de forma agressiva e levaram os pacientes à morte.

TERMOS DE INDEXAÇÃO: Epidemiologia, clínica, anatomopatologia, cães, linfoma folicular, linfoma indolente, linfoma multicêntrico, doenças de cães.

\section{INTRODUÇÃO}

Linfoma folicular (Working Formulation of Non-Hodgkin's Lymphomas for Clinical Usage), também denominado linfoma nodular (Classificação de Rappaport), linfoma das células do centrofolicular (Classificação de Lukes-Collins), linfoma centroblástico-centrocítico (Sistema Kiel), linfoma centrofolicular (Revised European-American Classification of Lymphoid Neoplasms, Sistema REAL), linfoma centro germinativo ou doença de Brill-Symmers (Ioachim 1994), é um distúrbio linfoproliferativo originário de linfócitos B, o qual se caracteriza anatomopatologicamente por um padrão arquitetural nodular e que envolve, predominantemente, os linfonodos (Harris \& Ferry 1992, Valli 2002, Harris et al. 2008). Em humanos é considerado um dos linfomas mais diagnosticados, representando $14,2 \%$ a $20,1 \%$ de todos os linfomas não Hodgkin (Morton et al. 2006, Aoki et al. 2008, Van Leeuwen et al. 2014). Por outro lado, essa é uma das formas de linfoma mais raras em cães, perfazendo apenas $0,6 \%$ a $7,5 \%$ dos casos (Valli et al. 2006, Guija de Arespacochaga et al. 2007, Ponce et al. 2010, Food-Kinapik et al. 2013). Por serem animais de companhia e, por consequência, sofrerem as mesmas influências ambientais que os humanos, os cães têm sido frequentemente considerados como um modelo para estudo dos linfomas não Hodgkin, em especial no que se refere à etiologia e à terapia (Vezzali et al. 2010, Ponce et al. 2010, Kimura 2012). A fim de entender melhor essa marcante diferença na prevalência do linfoma folicular entre humanos e cães, características epidemiológicas, clínicas, morfológicas, fenotípicas e genéticas desse tumor devem ser estudadas. Assim, o objetivo deste trabalho foi descrever os achados epidemiológicos, clínicos e anatomopatológicos observados em cães com linfoma folicular, a fim de fornecer dados para o estudo comparativo da doença e, adicionalmente, auxiliar Médicos Veterinários Patologistas no diagnóstico dessa condição em cães.

\section{MATERIAL E MÉTODOS}

Os casos incluídos neste estudo ocorreram entre os anos de 1965 e 2017, no Município de Santa Maria, localizado na Mesorregião do Centro Ocidental Rio-Grandense, $29^{\circ} 32^{\prime} 52^{\prime \prime}$ e $53^{\circ} 42^{\prime} 10^{\prime \prime}$ WGR. Foram considerados apenas casos diagnosticados como linfomas foliculares (sinônimo: linfomas centrofoliculares) (n=5). Para isso, os laudos de necropsias de cães realizadas no Laboratório de Patologia Veterinária da Universidade Federal de Santa Maria (LPV-UFSM), no referido período, foram revisados em busca de casos de linfoma com padrão nodular. Posteriormente, todos os casos $(n=5)$ foram reavaliados macroscopicamente por meio das imagens provenientes do arquivo de imagens do LPV-UFSM e, histologicamente, através da confecção de lâminas a partir do recorte dos tecidos embebidos em parafina com coloração pela Hematoxilina-Eosina (HE). 0 diagnóstico definitivo do tumor foi realizado com base nos critérios histológicos da Organização Mundial da Saúde (OMS) para a classificação dos tumores hematopoiéticos em humanos (Swerdlow et al. 2008), e para a classificação dos tumores hematopoiéticos em animais domésticos, publicados pelo Instituto de Patologia das Forças Armadas (AFIP) (Valli 2002). Com base nisso, foram selecionados apenas aqueles casos que apresentaram achados anatomopatológicos reconhecidos na literatura como linfomas foliculares $(n=5)$. E, fundamentando-se nessa mesma literatura, tais casos foram classificados em três graus (I, II ou III). Para isso, foi considerada a quantidade absoluta de centroblastos, contada no interior de diferentes nódulos neoplásicos, expressa em 10 campos de grande aumento (CGA, 400x). Para ser classificado como grau I, II ou III era necessário que fossem observados, respectivamente, 0-5 centroblastos/CGA, 6-15 centroblastos/CGA e $>15$ centroblastos/CGA. 0 grau III ainda foi subclassificado em graus IIIa ou IIIb. 0 critério utilizado para essa subclassificação foi a presença ou ausência de centrócitos. Casos diagnosticados como IIIa apresentavam uma pequena população de centrócitos distribuída esparsamente por entre os centroblastos. Casos diagnosticados como IIIb evidenciavam uma população monomórfica de centroblastos.

A fim de determinar a origem dos linfócitos neoplásicos, pelo menos um tecido acometido de cada um desses casos foi selecionado e submetido à técnica de imuno-histoquímica (IHQ) enzimática. A técnica empregada foi a imunomarcação para linfócitos B, utilizando-se anticorpo para CD20. Como de rotina, IHQ visando negatividade para linfócitos T, também foi realizada utilizando-se o anticorpo para CD3.

A técnica de imuno-histoquímica foi empregada seguindo o protocolo padronizado no Laboratório de Patologia Morfológica e Molecular (LAPMOL) da Faculdade de Medicina Veterinária e Zootecnia da Universidade de São Paulo (FMVZ-USP). Após a desparafinização e reidratação dos tecidos foi realizada a recuperação antigênica com solução de Tris-EDTA (pH 9,0) no forno de micro-ondas, em alta potência, por 10 minutos. Para realizar o bloqueio da peroxidase endógena foi utilizado peróxido de hidrogênio a 3\% por 20 minutos. O bloqueio das reações inespecíficas foi realizado com Protein Block por 10 minutos em temperatura ambiente. Como anticorpo primário foram utilizados os anticorpos policlonal anti-CD2 $0^{6}$ produzido em coelho, diluído 1:800 em diluente de anticorpo (Scy Tek, ATG 125), e anticorpo monoclonal anti-CD3 ${ }^{7}$ produzido em camundongo. Ambos os anticorpos foram incubados por 60 minutos em estufa a $37^{\circ} \mathrm{C}$. 0 anticorpo secundário e o Polímero Reveal Complement e Reveal HRP Conjugate HRP foram utilizados consecutivamente, incubados a $25^{\circ} \mathrm{C}$ por 30 minutos e revelados através da adição do cromógeno tetracloreto de 3-3' diaminobenzidina (DAB) por cinco minutos. A contra-coloração foi realizada com Hematoxilina de Harris. Tonsilas de cães foram utilizadas como controle positivo e o controle negativo foi obtido pela omissão do anticorpo primário. Para

6 RB9013-P. Thermo Fisher Scientific, 355 River Oaks Parkway, San Jose, CA, USA.

7 Clone F7.2.38; pré-diluído. Dako Cytomation, 6392 Via Real, Carpinteria, CA, USA. 
a obtenção do último, foi utilizado apenas o diluente de anticorpo. A imunomarcação para o CD20 foi classificada como leve, moderada ou acentuada, conforme estudos prévios (Maes et al. 2000).

Os dados clínicos e epidemiológicos a cerca de cada caso, foram obtidos a partir da revisão dos laudos e, quando possível, das fichas de atendimento pertencentes ao Serviço de Arquivos Veterinário (SAVE) do Hospital Veterinário Universitário da UFSM (HVU-UFSM).

\section{RESULTADOS}

\section{Epidemiologia}

Entre os anos de 1964 e 2017 foram necropsiados 8.899 cães. Destes, 100 morreram ou foram submetidos à eutanásia devido a complicações relacionadas ao linfoma. Do total de cães com linfoma, apenas 5\% foram diagnosticados com o padrão nodular. Dos cinco cães com linfoma folicular, dois eram machos (40\%) e três eram fêmeas (60\%). A idade dos cães afetados variou de 11 a 13 anos. Quatro dos cinco (80\%) cães eram de raça pura e um (20\%) não tinha raça definida (SRD). As raças puras incluíam Pastor Alemão (2/5), Pastor Belga (1/5) e Pinscher (1/5). Os cinco cães afetados foram submetidos à eutanásia devido ao avançado estadiamento da doença e encaminhados ao LPV-UFSM para a realização de necropsia (Quadro 1).

\section{Sinais clínicos}

Todos os cães demonstraram uma doença caracterizada, invariavelmente, por apatia, anorexia ou inapetência, dependendo do momento, esplenomegalia e linfadenomegalia superficial generalizada, ambas observadas através da palpação dos respectivos órgãos ao exame físico realizado na primeira consulta. Emagrecimento progressivo (3/5, 60\%), febre $(2 / 5,40 \%)$ e edema subcutâneo (2/5, 40\%), especialmente em membros pélvicos $(1 / 5,20 \%)$ e região cervical ventral $(1 / 5,20 \%)$, foram ocasionalmente descritos.

\section{Achados de necropsia}

Todos os cães necropsiados apresentavam linfonodos superficiais e profundos difusa e acentuadamente aumentados de volume (linfadenomegalia generalizada), brancacentos a levemente avermelhados (Fig.1) e macios ao toque. Ao corte, eram igualmente macios e deixavam fluir mínima quantidade de um líquido translúcido. A superfície de corte era úmida, brilhante, branca ou mosqueada de branco e vermelho, mas caracteristicamente pontilhada por dezenas a centenas de nódulos brancos, de tamanhos variáveis, multifocais ou coalescentes (padrão nodular), que não permitiam a delimitação corticomedular (Fig.2).

Em todos os casos, o baço estava difusa e acentuadamente aumentado de volume (esplenomegalia difusa), o que era evidenciado pelo arredondamento de suas bordas e pelo deslocamento em sua posição anatômica na cavidade abdominal (Fig.3). Três padrões macroscópicos foram identificados na superfície natural. Em um deles, observado em três dos cinco casos (60\%), a superfície era vermelha, lisa e repleta por miríades de pontos brancos, multifocais ou coalescentes, de tamanhos variáveis (padrão nodular) (Fig.4). Em outro padrão, visto em um dos cinco casos (20\%), a superfície era homogeneamente vermelha e lisa, porém sem os pontos brancos descritos nos três casos anteriores (Fig.5). No último padrão, visto também em um dos cinco casos (20\%), a superfície era marcadamente irregular, salpicada de pontos brancos elevados hemisfericamente (Fig.6). Apesar desses três padrões distintos, à superfície de corte, o baço era sempre caracterizado por um pontilhado brancacento (Fig.7) ou branco-rosado (Fig.8), brilhante (Fig.7) ou vítreo (Fig.8), aleatório, multifocal (Fig.7) ou coalescente (Fig.8), macroscopicamente semelhante ao descrito para hiperplasia difusa da polpa branca. Edema do tecido subcutâneo da região cervical ventral e de ambos os membros pélvicos foi visualizado em dois dos cinco casos (40\%). Outros achados de necropsia incluíam: broncopneumonia supurativa, doença articular degenerativa ("artrose") coxofemoral, endocardite da valva mitral, degeneração mixomatosa valvar (endocardiose)

Quadro 1. Achados epidemiológicos e anatomopatológicos do linfoma folicular canino

\begin{tabular}{|c|c|c|c|c|c|c|c|c|c|}
\hline Caso & Gênero & Raça & $\begin{array}{l}\text { Idade } \\
\text { (anos) }\end{array}$ & $\begin{array}{l}\text { Órgãos } \\
\text { afetados }\end{array}$ & $\begin{array}{c}\text { Apresentação } \\
\text { anatômica }\end{array}$ & $\begin{array}{c}\text { Grau } \\
\text { histológico }\end{array}$ & $\begin{array}{c}\text { Intensidade } \\
\text { na IHQ } \\
(\mathrm{CD} 20)^{*}\end{array}$ & $\begin{array}{l}\text { LRL ou } \\
\text { DTAN }^{* *}\end{array}$ & $\begin{array}{c}\text { Lesões } \\
\text { incidentais }\end{array}$ \\
\hline Canino 1 & Fêmea & $\begin{array}{l}\text { Pastor } \\
\text { Belga }\end{array}$ & 11 & $\begin{array}{l}\text { Linfonodos e } \\
\text { baço }\end{array}$ & Multicêntrico & IIIb variante & +++ & $\begin{array}{l}\text { Broncopneumonia } \\
\text { supurativa }\end{array}$ & $\mathrm{HNLE}^{\mathrm{a}}$ \\
\hline Canino 2 & Fêmea & $\begin{array}{l}\text { Pastor } \\
\text { Alemão }\end{array}$ & 12 & $\begin{array}{l}\text { Linfonodos e } \\
\text { baço }\end{array}$ & Multicêntrico & IIIa & ++ & $\begin{array}{l}\text { Endocardite valvar e } \\
\text { infartos esplênicos }\end{array}$ & - \\
\hline Canino 3 & Fêmea & Pinscher & 12 & $\begin{array}{l}\text { Linfonodos e } \\
\text { baço }\end{array}$ & Multicêntrico & IIIb & +++ & - & $\begin{array}{c}\text { Cicatriz } \\
\text { esplênica }\end{array}$ \\
\hline Canino 4 & Macho & $\begin{array}{l}\text { Pastor } \\
\text { Alemão }\end{array}$ & 11 & $\begin{array}{l}\text { Linfonodos e } \\
\text { baço }\end{array}$ & Multicêntrico & IIIb & +++ & - & $\begin{array}{c}\text { Artrose } \\
\text { coxofemoral } \\
\text { Endocardiose } \\
\text { mitral }\end{array}$ \\
\hline Canino 5 & Macho & $\mathrm{SRD}^{\mathrm{b}}$ & 13 & $\begin{array}{l}\text { Linfonodos e } \\
\text { baço }\end{array}$ & Multicêntrico & IIIa & +++ & - & $\begin{array}{c}\mathrm{HNH}^{\mathrm{c}} \\
\text { Cicatrizes renais }\end{array}$ \\
\hline
\end{tabular}




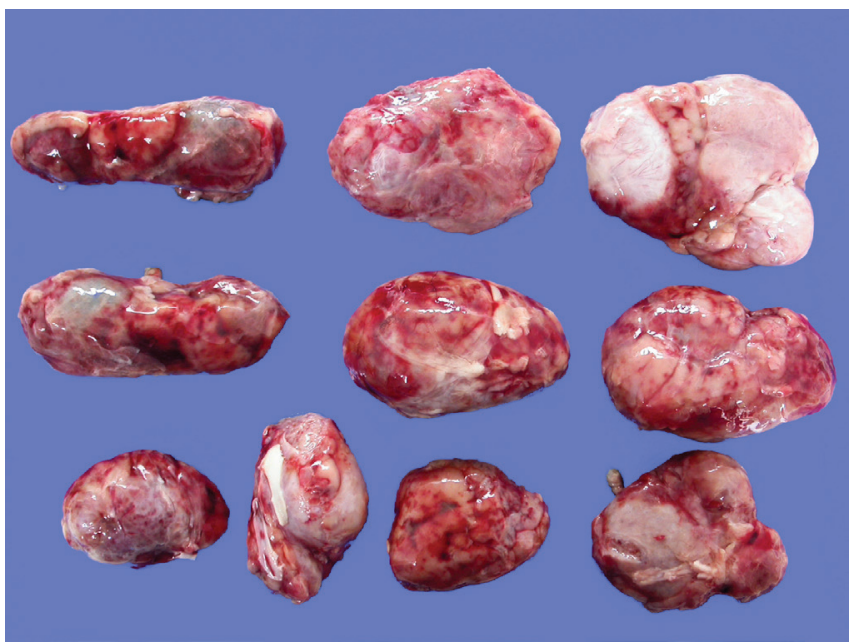

Fig.1. Linfoma folicular, linfonodos superficiais e profundos, cão. Acentuado aumento de volume (linfadenomegalia generalizada) e superfície natural moteada de branco e vermelho.

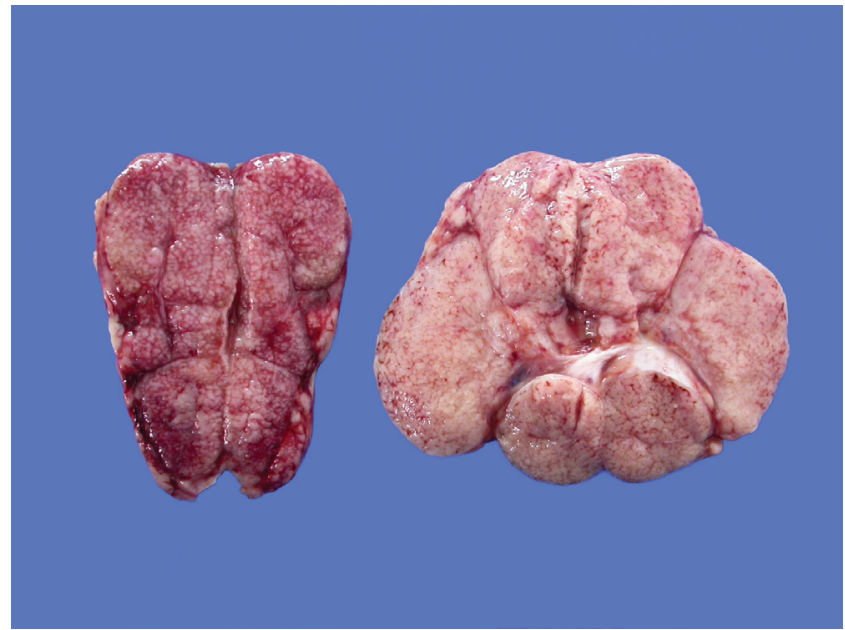

Fig.2. Linfoma folicular, linfonodos (superfície de corte), cão. Centenas de nódulos brancos, de tamanhos variáveis, multifocais ou coalescentes, não permitindo a delimitação corticomedular (padrão nodular).

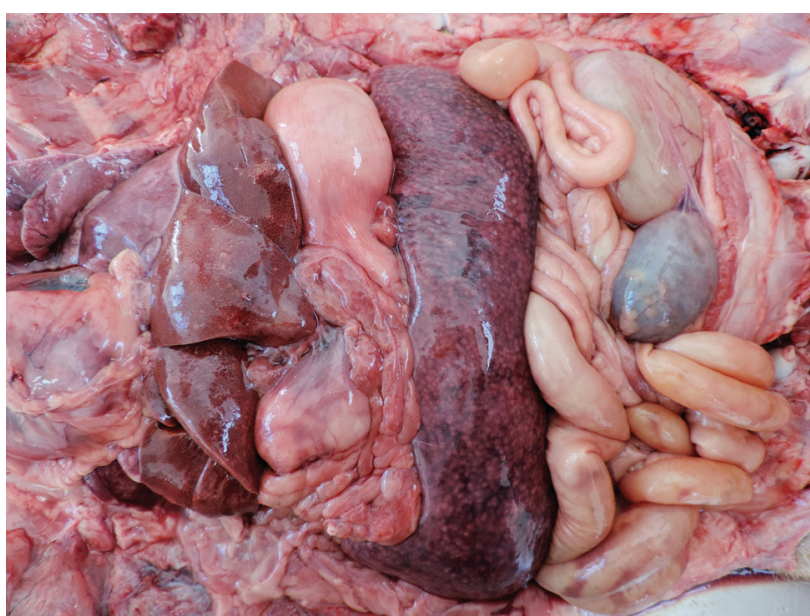

Fig.3. Linfoma folicular, baço, cão. Acentuado aumento de volume (esplenomegalia difusa) evidenciado pelo arredondamento de bordas e deslocamento da posição anatômica na cavidade abdominal.

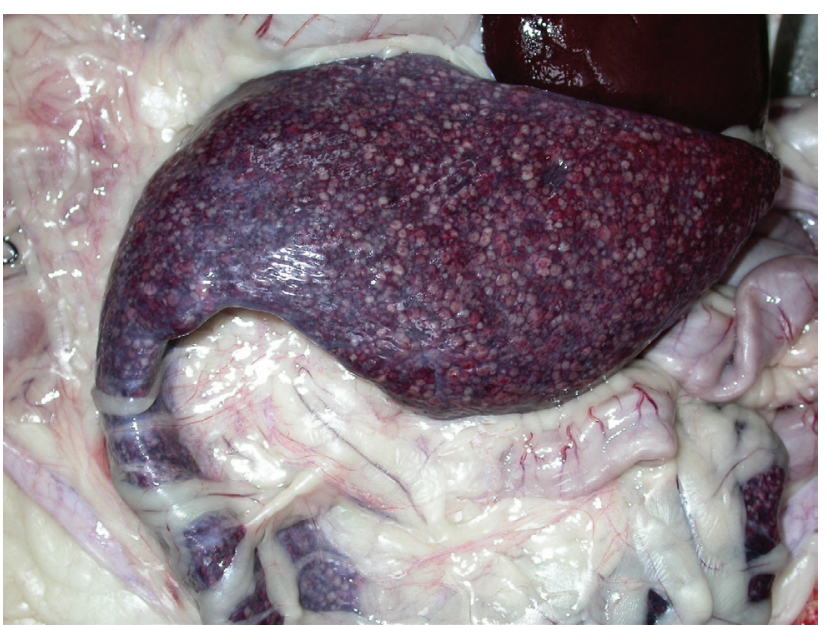

Fig.4. Linfoma folicular, baço (superfície natural), cão. Miríades de pontos brancos, multifocais ou coalescentes, de tamanhos variáveis (padrão nodular).

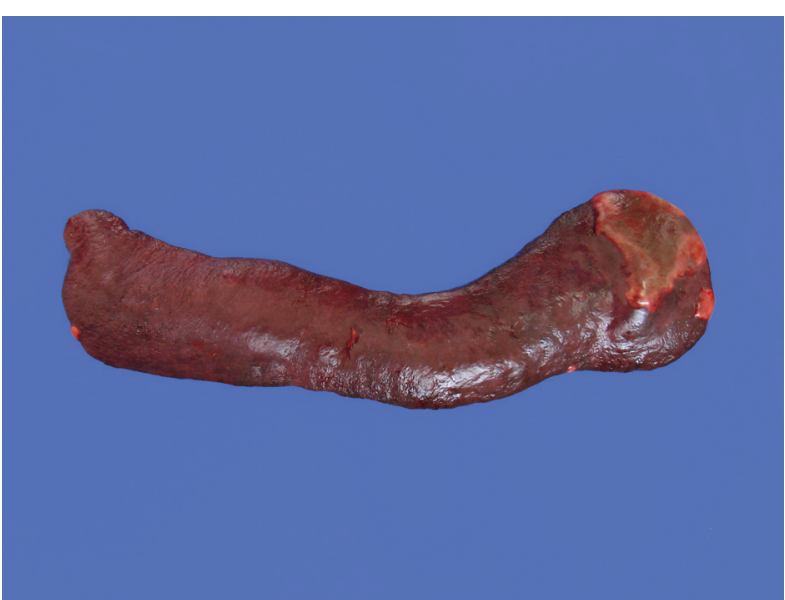

Fig.5. Linfoma folicular, baço (superfície natural), cão. Padrão homogêneo, não caracteristicamente nodular, mimetizando aquele visto no linfoma difuso. Observe o infarto focalmente extenso na extremidade ventral.

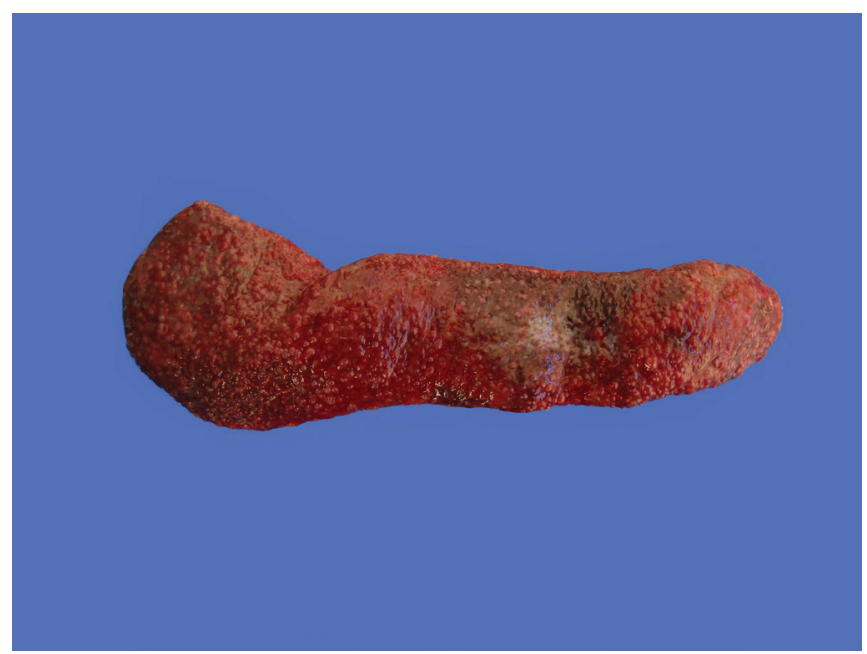

Fig.6. Linfoma folicular, baço (superfície natural), cão. Cápsula salpicada de pontos brancos e elevados hemisfericamente. 


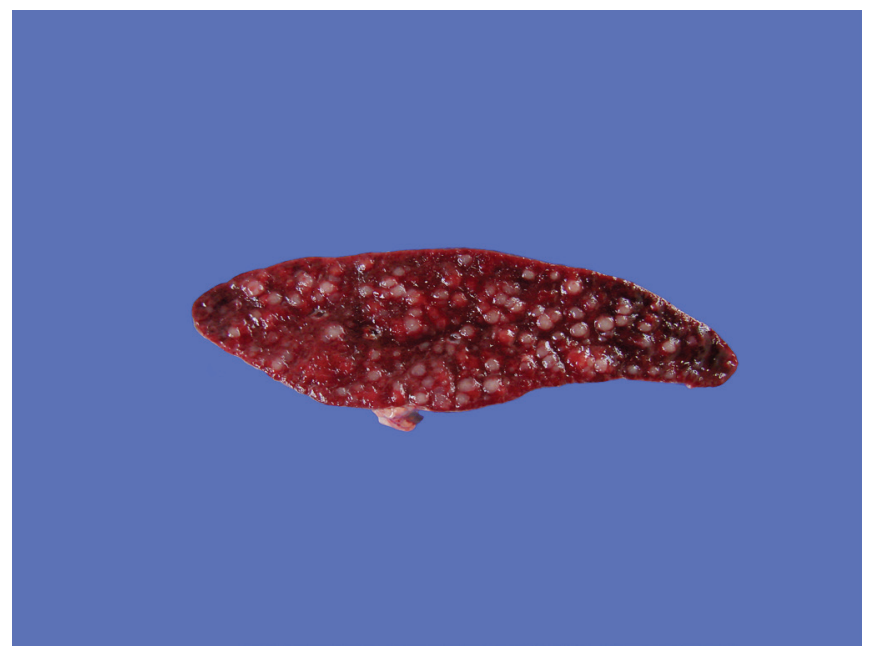

Fig.7. Linfoma folicular, baço (superfície de corte), cão. Presença de um pontilhado brancacento e brilhante distribuído multifocalmente.

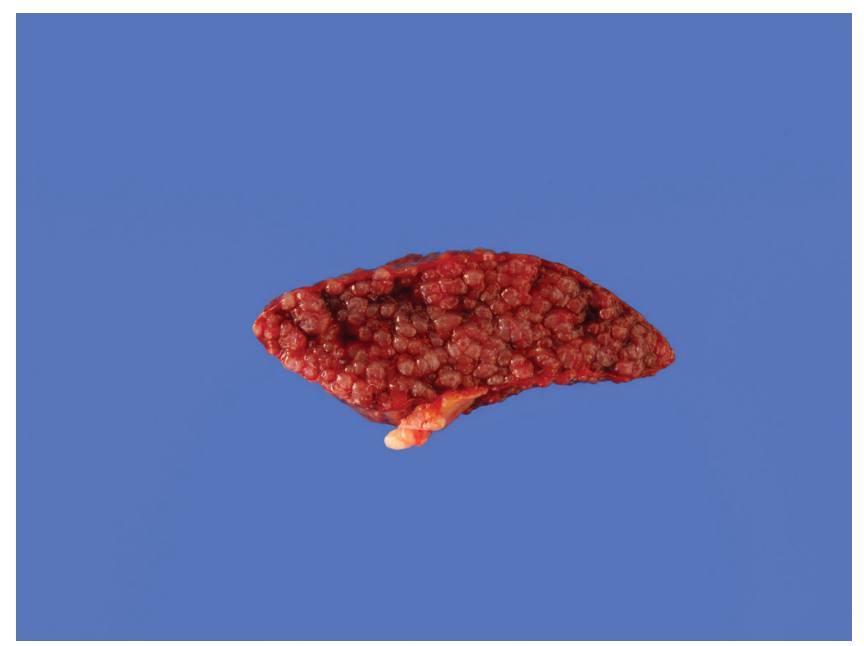

Fig.8. Linfoma folicular, baço (superfície de corte), cão. Presença de um pontilhado branco-rosado, vítreo e coalescente. Essa apresentação lembra muito féculas de mandioca granulada em formato de pequenas pérolas ("sagu").

(valva mitral), infartos esplênicos, hiperplasia nodular linfoide esplênica e cicatrizes esplênica e renal. Esses achados ocorreram em casos distintos ou em um mesmo caso. Alguns foram interpretados como relacionados ao linfoma ou à terapia antineoplásica, enquanto outros como achados incidentais (Quadro 1).

\section{Achados histopatológicos}

$\mathrm{Na}$ histopatologia, todos os casos apresentaram uma população densamente celular em linfonodos e baço, com padrão de organização caracterizado por nódulos de dimensões variáveis, moderada ou marcadamente definidos, não encapsulados, com zona do manto ausente e sem estroma perceptível (Fig.9). Nos linfonodos, esses nódulos invadiam a cápsula e obliteravam os seios subcapsulares e peritrabeculares. Nódulos neoplásicos dispostos intimamente, septados ou não por finas trabéculas de tecido conjuntivo, se estendiam desde a região cortical até a região medular, substituindo quase que totalmente o parênquima, não sendo possível visualizar os folículos linfoides, incluindo a sua "polarização", bem como as células hematopoiéticas componentes dos cordões medulares. No baço, o parênquima foi igualmente substituído por nódulos idênticos e proximamente relacionados. Tais nódulos eram compostos por células redondas distribuídas na forma de um manto (Fig.10) e separados por trabéculas esplênicas, por vezes, por discretos segmentos remanescentes da polpa vermelha. Graus variados de invasão da cápsula esplênica e trabéculas também foram observados em todos os cães.

Predominantemente, os linfócitos neoplásicos eram semelhantes a blastos (centroblastos - células blásticas-like), correspondendo duas a três vezes o tamanho de um pequeno linfócito. Apresentavam moderada quantidade de citoplasma homogêneo e eosinofílico. Núcleos redondos a ovais, constituídos por cromatina frouxamente arranjada ou vesicular, contendo um a quatro nucléolos grandes, eosinofílicos, proeminentes e localizados, em sua maioria, perifericamente, com frequencia em contato com a membrana nuclear. Mais raramente, células menores que um centroblasto, no entanto, maiores que um pequeno linfócito maduro, foram observadas, configurando a presença de centrócitos. Essas células eram caracterizadas por citoplasma escasso ou moderado, homogêneo e eosinofílico, núcleos redondos clivados ou reniformes, formados por cromatina frouxa, todavia, mais densamente arranjada quando comparada à de um centroblasto. Os nucléolos eram definidos como únicos, pequenos, basofílicos, inconspícuos e centrais. Com base na proporção de centroblastos, todos os casos (n=5, 100\%) foram classificados como Grau III. Baseado na heterogeneidade populacional, dois (40\%) dos cinco casos foram classificados como IIIa (Fig.11) e outros três $(60 \%)$ casos como IIIb (Fig.12). Em um caso $(1 / 5,20 \%$, classificado como IIIb, o padrão de distribuição celular e a morfologia dos centroblastos era distinta. Apesar de se dispor como um manto, semelhantemente aos outros, havia grande quantidade de macrófagos com citoplasma repleto de corpúsculos apoptóticos (corpos linfoglandulares ou corpos tingíveis), o que em menor aumento dava ao tecido um "padrão tipo céu estrelado" (Fig.13). Tais células tinham volumes intermediários, citoplasma homogêneo e eosinofílico e núcleos redondos a ovais, centrais, formados por cromatina moderadamente agregada, com nucléolos, múltiplos, pequenos e basofílicos, caracterizando pequenos centroblastos semelhantes aos linfócitos neoplásicos vistos no linfoma de Burkitt (Fig.14). Este caso foi classificado como IIIb variante $(1 / 3,33,3 \%)$. Em todos os casos, tanto no baço quanto nos linfonodos, havia variável quantidade de macrófagos dispersos aleatoriamente, contendo um pigmento granular castanho-dourado. Esse pigmento era fortemente positivo na marcação pelo Azul da Prússia e foi interpretado como hemossiderina. Em pelo menos um linfonodo de cada caso revisado, os seios medulares e, ocasionalmente, os seios corticais, mostravam-se repletos de eritrócitos (congestão). No baço, em alguns casos avaliados $(2 / 5,40 \%)$, eram notadas manchas amarelo-ouro livres nas trabéculas, mas também no citoplasma de macrófagos epitelioides e de células gigantes multinucleadas (hematoidina). 


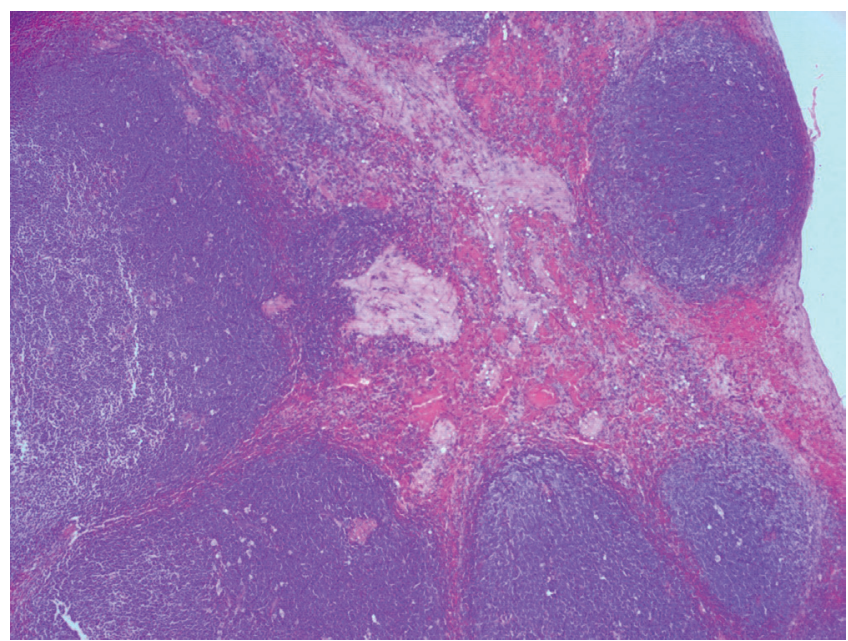

Fig.9. Linfoma folicular, baço, cão. Parênquima parcialmente substituído por grandes nódulos linfoides coalescentes. HE, obj.4x.

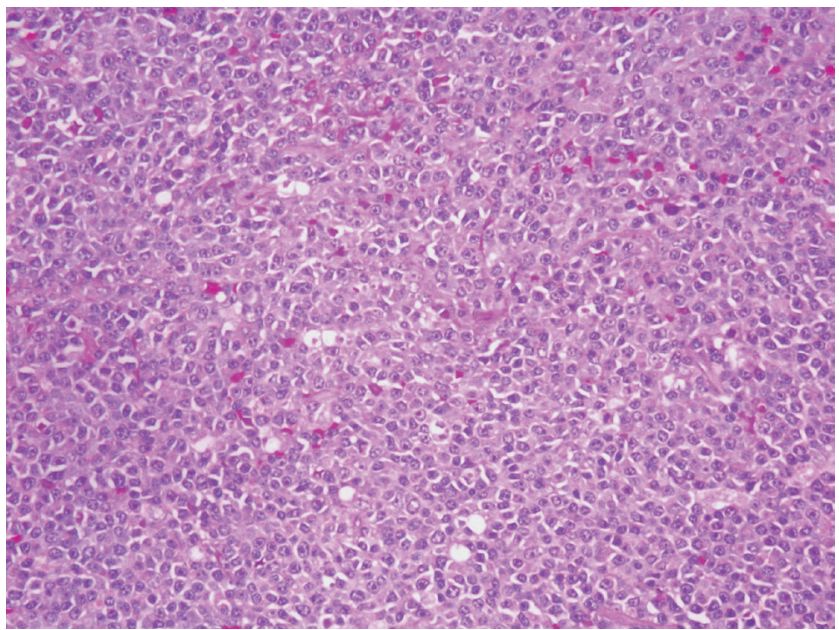

Fig.10. Linfoma folicular, baço, cão. Maior aumento da Fig.9. Observe o padrão monótono disposto como um manto de células e a ausência quase absoluta de estroma fibrovascular. HE, obj.10x.

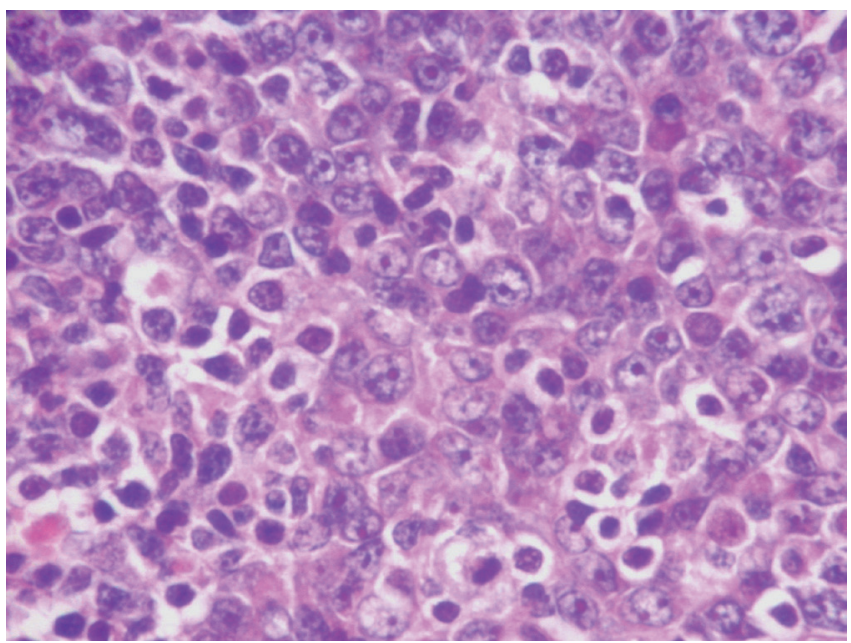

Fig.11. Linfoma folicular, linfonodo, cão. Há um pequeno número de centrócitos distribuídos esparsamente por entre uma população predominante de centroblastos, o que caracteriza o Grau IIIa. HE, obj.40x.

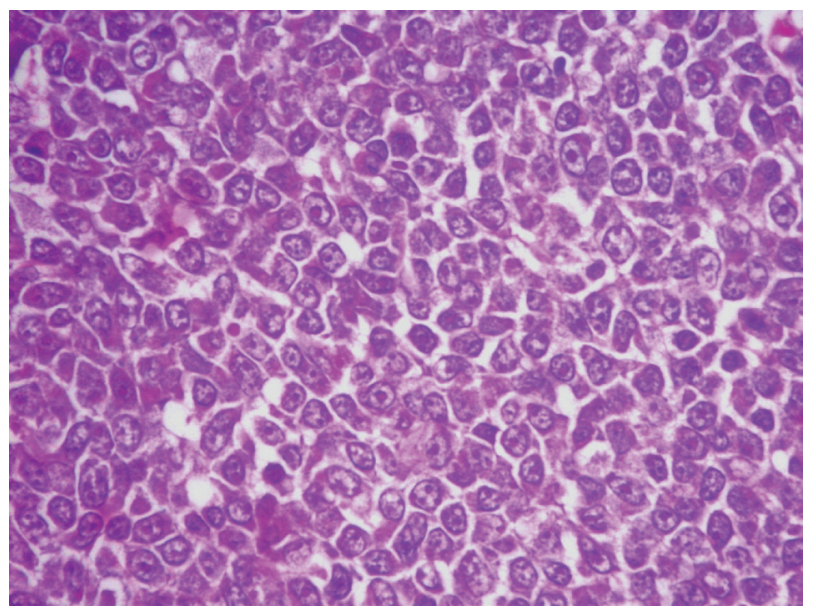

Fig.12. Linfoma folicular, linfonodo, cão. População monomórfica de centroblastos na ausência de centrócitos (Grau IIIb). HE, obj.40x.

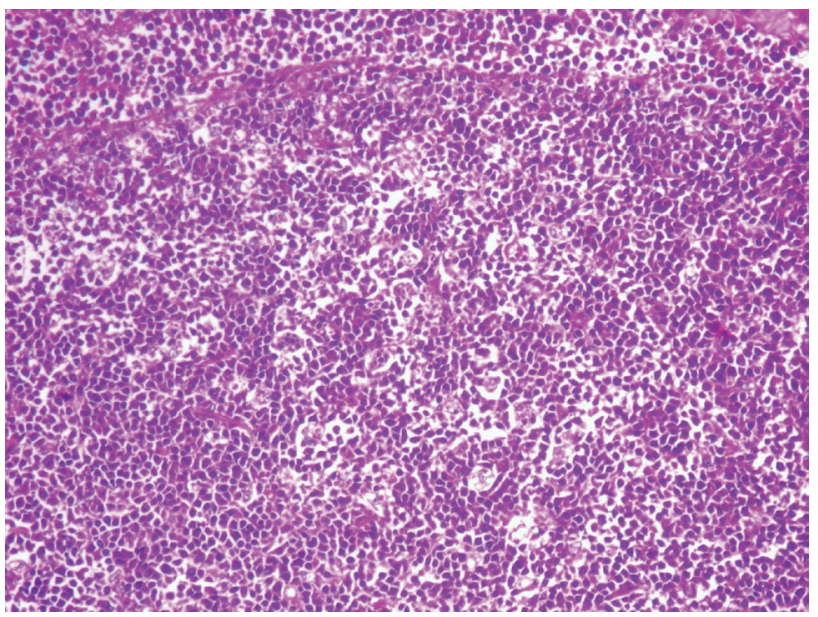

Fig.13. Linfoma folicular, linfonodo, cão. Grande quantidade de áreas claras em meio a um fundo celular escuro, o que dá ao tecido, em baixa magnitude, um "padrão tipo céu-estrelado". HE, obj.10x.

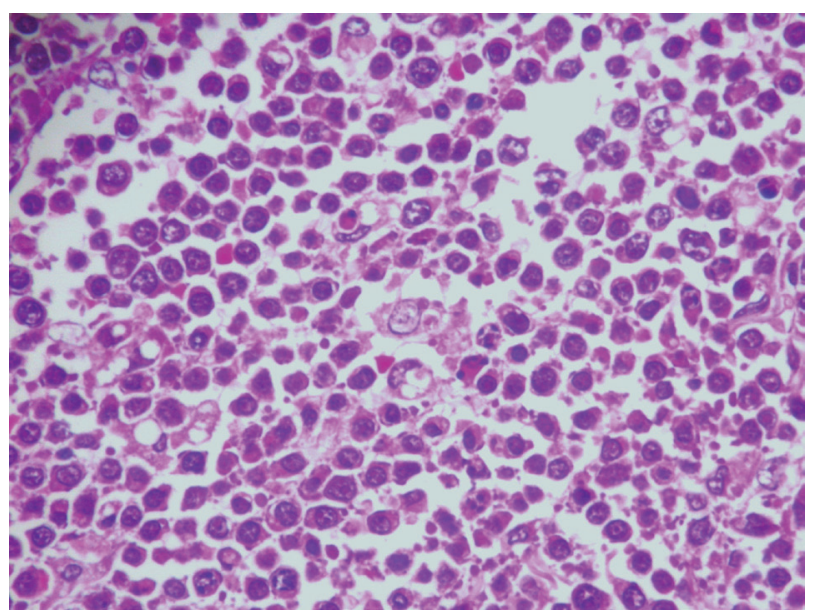

Fig.14. Linfoma folicular, linfonodo, cão. Maior aumento da Fig.13. Observe que a população linfoide é composta de pequenos centroblastos, caracterizados por núcleos constituídos por cromatina mais densamente arranjada. Tais células são semelhantes aos linfócitos neoplásicos vistos no linfoma de Burkitt. A presença dessas células caracteriza uma variante do Grau IIIb. Macrófagos vacuolizados e com corpúsculos linfoglandulares localizados ao centro da figura. HE, obj.40x. 


\section{Achados imuno-histoquímicos}

Na imuno-histoquímica, as células neoplásicas foram positivas para o marcador de linfócitos B (anti-CD20) em todos os casos analisados, tanto nos tumores nodais quanto esplênicos (Fig.15). Quanto à intensidade da imunomarcação, a maior parte dos casos foi considerada como acentuada (4/5, 80\%). Imunomarcação moderada ocorreu em um caso $(1 / 5,20 \%)$ e imunomarcação discreta não foi observada. Quanto ao padrão morfológico de imunomarcação, as células positivas possuíam citoplasma finamente granular, com maior intensidade na região próxima à membrana citoplasmática (Fig.16). 0 marcador para linfócitos T (CD3) apresentou reatividade apenas em pequenos grupos de linfócitos normais, distribuídos aleatoriamente pelo tecido remanescente.

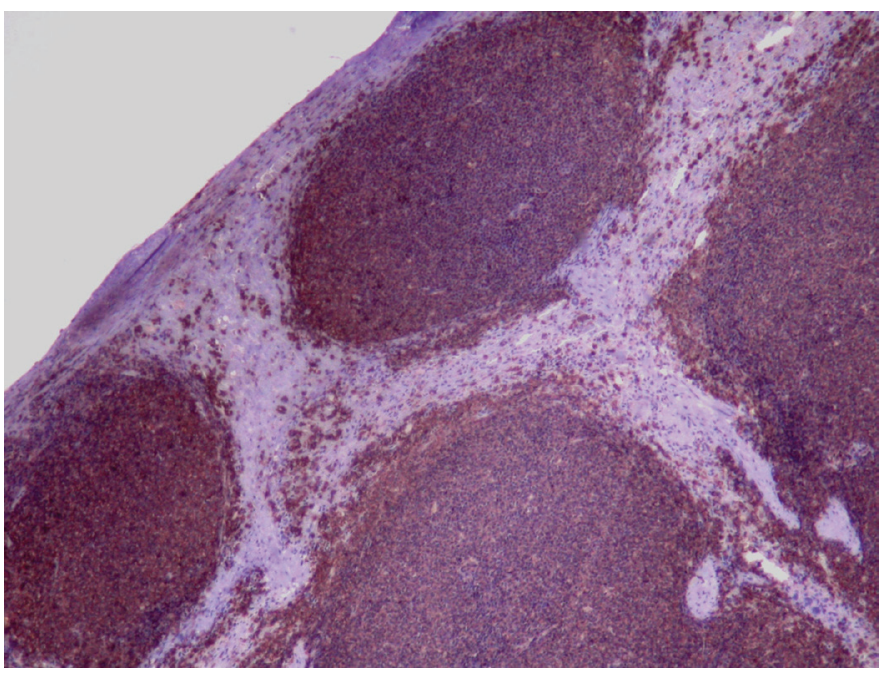

Fig.15. Linfoma folicular, baço, cão. Nódulos linfoides acentuadamente imunomarcados para CD20. Imuno-histoquímica, obj.4x.

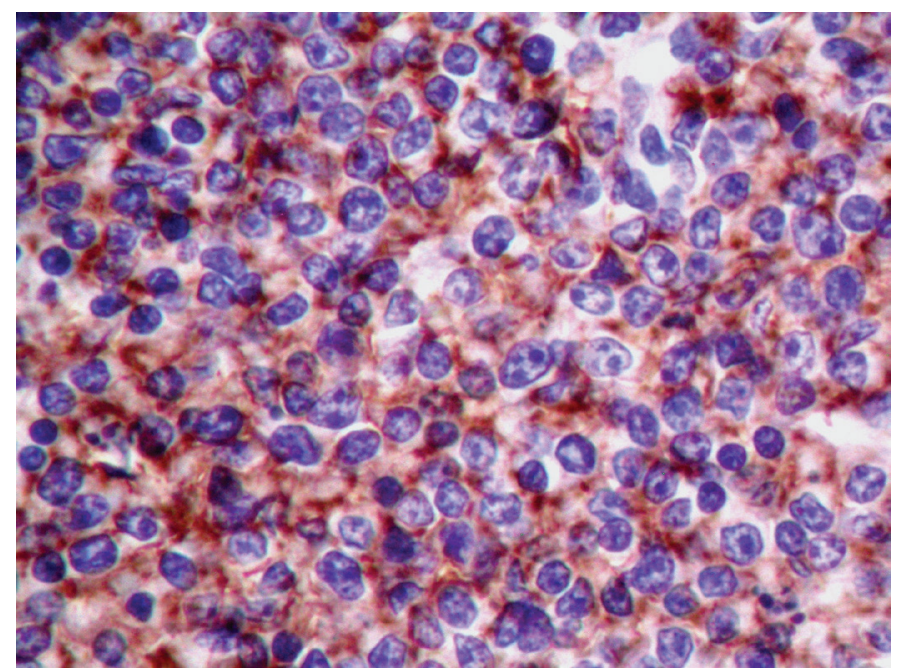

Fig.16. Linfoma folicular, baço, cão. Linfócitos neoplásicos com padrão de imunomarcação para CD20 caracterizado por citoplasma finamente granular, com maior intensidade na região próxima à membrana citoplasmática. Imuno-histoquímica, obj.40x.

\section{DISCUSSÃO}

A maior parte da literatura considera o linfoma folicular em cães como uma condição incomum ou rara, pois perfaz 6,6\% (4/60) a 7,5\% (5/66) dos linfomas não Hodgkin nos Estados Unidos (EUA) (Valli et al. 2006, Flood-Kinapik et al. 2012) e entre 0,5\% (3/608) e 1,2\% na Europa (Guija de Arespacochaga et al. 2007, Ponce et al. 2010), perfazendo um total de 13 casos descritos na literatura. Estes dados são semelhantes à prevalência encontrada neste estudo $(5 \%$ dos casos nessa espécie). Assim como cães, os gatos, equinos, bovinos e ratos, são também raramente acometidos pelo linfoma folicular, representando, respectivamente, $0,5 \%$, $0,49 \%, 0,33 \%$ e $0,22 \%$ de todos os linfomas nessas espécies (Frith 1988, Vernau et al. 1992, Valli et al. 2000, Durham et al. 2013). Dessemelhante, o linfoma folicular é o segundo linfoma mais comum em humanos, atingindo cerca de $20 \%$ dos casos de linfoma não Hodgkin tanto nos EUA como na Europa (Al-Hamadani et al. 2015). Entretanto, em alguns países do Leste e do Sudeste Asiático, a prevalência do linfoma folicular é muito similar à observada em cães, equivalendo 2,9\% a 5,9\% dos casos de linfoma não Hodgkin (Kim et al. 2011). Tendo como base estudos realizados na medicina humana (Anderson et al. 1998, Intragumtornchai et al. 2017), uma possível explicação para essa diferença nas prevalências poderia ser a complexa inter-relação existente entre a suscetibilidade genética e diferentes fatores ambientais.

Quanto aos órgãos afetados, uma diferença significativa foi observada entre os nossos resultados e os dados já publicados na literatura consultada. Segundo alguns autores (Valli et al. 2006, Guija de Arespacochaga et al. 2007, Ponce et al. 2010, Flood-Kinapik et al. 2012), os linfonodos foram os únicos órgãos afetados em todos os casos diagnosticados como linfoma folicular, diferentemente de nossos achados, sendo que todos os casos também apresentaram envolvimento esplênico, visto macroscopicamente como esplenomegalia difusa, incluindo três diferentes padrões de apresentação macroscópica. Em humanos, linfomas foliculares também afetam baço, medula óssea, o anel linfático de Waldeyer (formado pelas tonsilas faríngea, palatina e lingual) e o sangue periférico, manifestando-se como linfocitose, em aproximadamente 10\% dos pacientes (Harris \& Ferry 1992, Harris et al. 2008). 0 envolvimento do trato gastrointestinal (TGI) e dos tecidos moles pode ocorrer como parte de um linfoma folicular multicêntrico e, raramente, outros órgãos não hematopoiéticos podem ser primariamente afetados, incluindo pele, TGI (particularmente o duodeno), anexos do globo ocular, mama e testículos (Harris et al. 2008). Além do evidente envolvimento do baço e linfonodos no linfoma folicular, as demais alterações não foram observadas nos cães incluídos neste estudo.

A aparência histológica dos linfomas foliculares varia consideravelmente de acordo com o grau de diferenciação das células neoplásicas e com o estádio de desenvolvimento tumoral (Harris \& Ferry 1992, Valli 2007, Harris et al. 2008). Linfomas foliculares em estádio avançado de desenvolvimento apresentam um padrão de organização celular caracterizado por nódulos neoplásicos intimamente relacionados, não sendo possível visualizar com clareza os folículos linfoides, contudo, em estádios iniciais da doença, os folículos ainda são mantidos, incluindo sua "polarização" (Valli 2007, Harris et al. 2008). Dos tumores incluídos neste estudo, todos se apresentavam em 
estádio avançado de desenvolvimento. Embora seja mais comum o diagnóstico de linfomas foliculares em estádios avançados (Valli et al. 2006, Ponce et al. 2010, Flood-Kinapik 2012), tumores em fase inicial podem, ocasionalmente, ocorrer e ser um desafio ao diagnóstico com base apenas na histopatologia, considerando a hiperplasia folicular linfoide, o principal diagnóstico diferencial para o tumor nessa fase (Nathwani et al. 1981, Valli 2007). Nestes casos, para diferenciação entre linfoma folicular e hiperplasia folicular os seguintes critérios deverão ser incluídos: 1) menor quantidade de nódulos por unidade de área, 2) diminuição ou ausência de área interfolicular, o que dá, em menor aumento, um padrão multinodular do tipo "back-to-back", 3) formatos e diâmetros semelhantes entre os nódulos, que se tornam geralmente redondos, 4) perda parcial ou total da "polarização", principalmente perda da zona do manto, 5) obliteração nodal, ou seja, não restrição da proliferação ao córtex, com evidente invasão medular, 6) maior uniformidade celular e, geralmente, 7) grau mitótico menos elevado (Nathwani et al. 1981).

Em relação ao subtipo histológico, dos 13 casos publicados na literatura (Valli et al. 2006, Guija de Arespacochaga et al. 2007, Ponce et al. 2010, Flood-Kinapik et al. 2012), a maioria $(10 / 13,76,9 \%)$ foi classificada como Grau III, enquanto os demais como Grau II $(3 / 13,23,1 \%)$. Estes dados foram semelhantes aos nossos resultados. Dessemelhante, em humanos, linfomas foliculares de Grau I ocorrem mais frequentemente, correspondendo a $36,3 \%$ dos casos, seguido dos linfomas de Grau II $(33,6 \%)$ e de Grau III $(30,1 \%=27,6 \%$ Grau IIIa e 2,5\% Grau IIIb) (Cabanillas et al. 2016).

Na medicina humana, o linfoma folicular de Grau III, principalmente Grau IIIb, apresenta comportamento biológico mais agressivo, com menor resposta à terapia e, consequentemente, um curto período de sobrevida (Harris \& Ferry 1992, Federico et al. 2000). Isso difere do que ocorre com os linfomas foliculares de graus I e II, que exibem melhor resposta ao tratamento, proporcionando maior sobrevida (entre cinco e 10 anos) e, por isso, denominados por alguns autores como "linfomas indolentes" (Federico et al. 2000, Campo et al. 2011, Cabanillas et al. 2016). Apesar disso, existem variações entre pacientes no que tange a resposta ao tratamento, assim, linfomas foliculares de graus I e II podem, às vezes, apresentar comportamento biológico inconsistente com o diagnóstico histopatológico (Harris \& Ferry 1992, Cabanillas et al. 2016). Em nosso estudo, 40\% dos casos foram incluídos como IIIa e 60\% como IIIb, no entanto, não há dados na literatura veterinária a respeito do real comportamento biológico do linfoma folicular em cães, principalmente quanto aos seus diferentes graus. Por esse motivo, é difícil realizar um estudo comparativo com humanos, além disso, alguns autores consideram o linfoma folicular, independentemente do seu grau, como um linfoma indolente (Valli et al. 2006, FloodKinapik et al. 2012). Fundamentando-se na literatura humana (Harris \& Ferry 1992, Campo et al. 2011, Cabanillas et al. 2016), acreditamos que o comportamento biológico do linfoma folicular em cães, possa ser semelhante ao o que ocorre em humanos, todavia, em medicina veterinária, a denominação de "linfoma indolente" deve ser cuidadosamente aplicada, particularmente no que se refere aos linfomas foliculares de Grau III, à exemplo de nosso estudo, uma vez que todos os cães afetados apresentaram disseminação esplênica e morte associada ao tumor.

\section{CONCLUSÃO}

Linfomas foliculares demonstraram ser uma rara forma de distúrbio linfoproliferativo em cães também em nossa região (região central do RS, Brasil) e, diferentemente do que ocorre em humanos e de como vem sendo relatado em cães ("linfomas indolentes"), todos os casos evoluíram de forma agressiva e com desfecho fatal, assemelhando-se muito, do ponto de vista do comportamento biológico, aos linfomas difusos não Hodgkin.

\section{REFERÊNCIAS}

Al-Hamadani M., Habermann T.M., Cerhan J.R., Macon W.R., Maurer M.J. \& Go R.S. 2015. Non-Hodgkin lymphoma subtype distribution, geodemographic patterns, and survival in the US: A longitudinal analysis of the National Cancer Data Base from 1998 to 2011. Am. J. Hemathol. 90(9):790-795. <http://dx.doi.org/10.1002/ajh.24086><PMid:26096944>

Anderson J.R., Armitage J.O. \& Weisenburger D.D. 1998. Epidemiology of the non-Hodgkin's lymphomas: distributions of the major subtypes differ by geographic locations. Non-Hodgkin's Lymphoma Classification Project. Ann. Oncol. 9(7):717-720. <http://dx.doi.org/10.1023/A:1008265532487> <PMid:9739436>

Aoki R., Karube K., Sugita Y., Nomura Y., Shimizu K., Kimura Y., Hashikawa K., Suefuji N., Kikuchi M. \& Ohshima K. 2008. Distribution of malignant lymphoma in Japan: analysis of 2260 cases, 2001-2006. Pathol. Intern. 58(3):174-182. <http://dx.doi.org/10.1111/j.1440-1827.2007.02207. $\mathrm{x}><$ PMid:18251781>

Cabanillas F., Rivera N. \& Pardo W.I. 2016. Indolent lymphomas that presents clinically aggressive features: a subset of low-grade lymphomas with a behavior inconsistent with the histologic diagnosis. Clin. Lymph. Myel. Leuk. 16(10):550-557. <http://dx.doi.org/10.1016/j.clml.2016.08.011> <PMid:27618361>

Campo E., Swerdlow S.H., Harris N.L., Pileri S., Stein H. \& Jaffe E.S. 2011. The 2008 WHO classification of lymphoid neoplasms and beyond: evolving concepts and practical applications. Blood 117(19):5019-5032.<http:// dx.doi.org/10.1182/blood-2011-01-293050> <PMid:21300984>

Durham A.C., Pillitteri C.A., San Myint M. \& Valli V.E. 2013. Two hundred three cases of equine lymphoma classified according to the World Health Organization (WHO) classification criteria. Vet. Pathol. 50(1):86-93. <http://dx.doi.org/10.1177/0300985812451603><PMid:22700849>

Federico M., Vitolo U., Zinzani P.L., Chisesi T., Clo V., Bellesi G., Magagnoli M., Liberati M., Boccomini C., Niscola P., Pavone V., Cuneo A., Santini G., Brugiatelli M., Baldini L., Rigacci L. \& Resegotti L. 2000. Prognosis of follicular lymphoma: a predictive model based on a retrospective analysis of 987 cases. Blood 95(3):783-789. <PMid:10648386>

Flood-Knapik K.E., Durham A.C., Gregor T.P., Sánchez M.D., Durney M.E. \& Sorenmo K.U. 2012. Clinical, histopathological and immunohistochemical characterization of canine indolent lymphoma. Vet. Comp. Oncol. 11(4):272286. <http://dx.doi.org/10.1111/j.1476-5829.2011.00317.x>

Frith C.H. 1988. morphologic classification and incidence of hematopoietic neoplasms in the Sprague-Dawley rat. Toxicol. Pathol. 16(4):451-457. <http://dx.doi.org/10.1177/019262338801600405><PMid:3065912>

Guija de Arespacochaga A., Schwendenwein I. \& Weissenböck H. 2007 Retrospective study of 82 cases of canine lymphoma in Austria based on the Working Formulation and Immunophenotyping. J. Comp. Pathol 136(2-3):186-192. <http://dx.doi.org/10.1016/j.jcpa.2007.01.009> $<$ PMid:17416237>

Harris N.L. \& Ferry J.A. 1992. Follicular lymphoma and related disorders (germinal center lymphomas), p.1432-1462. In: Knowles D.M. (Ed.), Neoplastic Hematopathology. Williams and Wilkins, Maryland.

Harris N.L., Swerdlow S.H., Jaffe E.S., Ott G., Nathwani B.N., De Jong D., Yoshino T., Spagnolo D., Pileri S.A., Stein H., Thiele J. \& Vardiman J.W. 2008. Follicular lymphoma, p.220-226. In: Swerdlow S.H., Campo E., Harris N.L., Jaffe E.S., 
Pileri S.A., Stein H., Thiele J. \& Vardiman J.W. (Eds), WHO Classification of Tumours of Haematopoietic and Lymphoid Tissues. IARC Press, Lyon, France.

Intragumtornchai T., Bunworasate U., Wudhikarn K., Lekhakula A., Julamanee J., Chansung K., Sirijerachai C., Norasetthada L., Nawarawong W., Khuhapinant A., Siritanaratanakul N., Numbenjapon T., Prayongratana K., Chuncharunee S., Niparuck P., Suwanban T., Kanitsap N., Wongkhantee S., Pornvipavee R., Wong P., Makruasi N., Wannakrairot P., Assanasen T., Sukpanichnant S., Boonsakan P., Kanoksil W., Ya-In C., Kayasut K., Mitranun W. \& Warnnissorn N. 2017. Non-Hodgkin lymphoma in South East Asia: an analysis of the histopathology, clinical features, and survival from Thailand. Hematol. Oncol. 35(1):1-9. <PMid:28332735>

Ioachim H.L. 1994. Follicular (nodular) lymphoma, p.366-382. In: Ioachim H.L. (Ed.), Limpho Node Pathology. Lippincott Company, Washington, DC.

Kim J.M., Ko Y.H., Lee S.S., Huh J., Kang C.S., Kim C.W., Kang Y.K., Go J.H., Kim M.K., Kim W.S., Kim Y.J., Kim H.J., Kim H.K., Nam J.H., Moon H.B., Park C.K., Park T., Oh Y.H., Lee D.W., Lee J.S., Lee J., Lee H.L., Lim S.C., Jang K.Y., Chang H.K., Jeon Y.K., Jung H.R., Cho M.S., Cha H.J., Choi S.J., Han J.H., Hong S.H. \& Kim I. 2011. WHO classification of malignant lymphomas in Korea: report of the Third Nationwide Study. Korean. J. Pathol. 45(3):254-260. <http:// dx.doi.org/10.4132/KoreanJPathol.2011.45.3.254>

Kimura K.C. 2012. Linfoma canino: papel do meio ambiente. Tese de Doutorado. Disponível em <http://www.teses.usp.br/teses/disponiveis/10/10133/ tde-05082013-165249/pt-br.php> Acesso em 24 out. 2016.

Maes B., Achten R., Demunter A., Peeters B., Verhoef G. \& De Wolf-Peeters C. 2000. Evaluation of $B$ cell lymphoid infiltrates in bone marrow biopsies by morphology, immunohistochemistry, and molecular analysis. J. Clin. Pathol. 53(11):835-840. <http://dx.doi.org/10.1136/jcp.53.11.835> <PMid:11127265>

Morton L.M., Wang S.S., Devesa S.S., Hartge P., Weisenburger D.D. \& Linet M.S. 2006. Lymphoma incidence patterns byWHO subtype in the United States, 1992-2001. Blood 107(1):265-276. <http://dx.doi.org/10.1182/ blood-2005-06-2508><PMid:16150940>

Nathwani B.N., Winberg C.D., Diamond L.W., Bearman R.M. \& Kim H. 1981. Morphologic criteria for the differentiation of follicular lymphoma from florid reactive follicular hyperplasia: a study of 80 cases. Cancer 48(8):17941806. <http://dx.doi.org/10.1002/1097-0142(19811015)48:8<1794::AIDCNCR2820480817>3.0.CO;2-M><PMid:7026023>

Ponce F., Marchal T., Magnol J.P., Turinelli V., Ledieu D., Bonnefont C., Pastor M., Delignette M.L. \& Fournel-Fleury C. 2010. A morphological study of 608 cases of canine malignant lymphoma in France with a focus on comparative similarities between canine and human lymphoma morphology. Vet. Pathol. 47(3):414-433.<http://dx.doi.org/10.1177/0300985810363902> <PMid:20472804>

Swerdlow S.H., Campo E., Harris N.L., Jaffe E.S., Pileri S.A., Stein H., Thiele J. \& Vardiman J.W. 2008. Mature B-cell neoplasms, p.179-267. In: Swerdlow S.H., Campo E., Harris N.L., Jaffe E.S., Pileri S.A., Stein H., Thiele J. \& Vardiman J.W. (Eds), WHO Classification of Tumours of Haematopoietic and Lymphoid Tissues. IARC Press, Lyon, France.

Valli V.E. 2002. Cell and NK-cell lymphoid neoplasms, p.39-46. In: Valli V.E., Jacobs R.M., Parodi A.L., Vernau W. \& Moore P.F. (Eds), Histological Classification of Hematopoietic Tumors of Domestic Animals. Armed Forces Institute of Pathology, Washington, DC.

Valli V.E. 2007. Follicular lymphoma, p.215-227. In: Valli V.E. (Ed.), Veterinary Comparative Hematopathology. Blackwell Publishing Ltd, Oxford. <http:// dx.doi.org/10.1002/9780470344545>.

Valli V.E., Vernau W., De Lorimier L.P., Graham P.S. \& Moore P.F. 2006. Canine indolent nodular lymphoma. Vet. Pathol. 43(3):241-256. <http://dx.doi. org/10.1354/vp.43-3-241><PMid:16672571>

Valli V.E., Jacobs R.M., Norris A., Couto C.G., Morrison W.B., McCaw D., Cotter S., Ogilvie G. \& Moore A. 2000. The histologic classification of 602 cases of feline lymphoproliferative disease using the National Cancer Institute working formulation. J. Vet. Diagn. Invest. 12(4):295-306. <http://dx.doi. org/10.1177/104063870001200401><PMid:10907857>

van Leeuwen M.T., Turner J.J., Joske D.J., Falster M.O., Srasuebkul P., Meagher N.P., Grulich A.E., Giles G.G. \& Vajdic C.M. 2014. Lymphoid neoplasm incidence by WHO subtype in Australia 1982-2006. Int. J. Cancer 135(9):2146-2156. <http://dx.doi.org/10.1002/ijc.28849><PMid:24639369>

Vernau W., Valli V.E., Dukes T.W., Jacobs R.M., Shoukri M. \& Heeney J.L. 1992. Classification of 1,198 cases of bovine lymphoma using the National Cancer Institute working formulation for human non-Hodgkin's lymphomas. Vet. Pathol. 29(3):183-195.<http://dx.doi.org/10.1177/030098589202900301> <PMid:1621329>

Vezzali E., Parodi A.L., Marcato P.S. \& Bettini G. 2010. Histopathologic classification of 171 cases of canine and feline non-Hodgkin lymphoma according to the WHO. Vet. Comp. Oncol. 8(1):38-49. <http://dx.doi. org/10.1111/j.1476-5829.2009.00201.x><PMid:20230580> 